\title{
The Role of Aromatic Schiff Bases in the Dyes Techniques
}

\author{
Karema Masoude Abuamer ${ }^{1}$, Abdussalam Ali Maihub ${ }^{1 *}$, Marei Miloud El-Ajaily ${ }^{2}$, \\ Abdunnaser Mohamed Etorki1 ${ }^{*}$, Mortaja Mohamed Abou-Krisha ${ }^{3}$, Majda Albashir Almagani ${ }^{1}$ \\ ${ }^{1}$ Chemistry Department, Faculty of Science, Tripoli University, Tripoli, Libya \\ ${ }^{2}$ Chemistry Department, Faculty of Science, Benghazi University, Benghazi, Libya \\ ${ }^{3}$ Chemistry Department, Faculty of Science, South Valley University, Gena, Egypt \\ Email: " maihubchem@hotmail.com,
}

Received 4 December 2013; revised 10 January 2014; accepted 17 January 2014

Copyright (C) 2014 by authors and Scientific Research Publishing Inc.

This work is licensed under the Creative Commons Attribution International License (CC BY).

http://creativecommons.org/licenses/by/4.0/

(c) (1) Open Access

\begin{abstract}
Anil compounds are Schiff bases derived from aniline moiety containing phenyl or substituted phenyl group, which sometimes called Azo dyes. These Schiff bases can be directly prepared from aromatic amine with aromatic carbonyl groups, which are stable and can be manipulated under different and suitable conditions. The phenomena of coordination of Schiff bases with metal ions give the Schiff bases the good advantages to be introduced in the dyes synthesis. The classification of dyes is based on the chemical structure or on the basis of the chromophoric system. The metal complex dyes are combinations of dyestuff and metal ions, in which the coordination complex can be applied or used to be improvement factors in dye techniques. The investigation and the characterization of the resulted dyes were performed by using different physical techniques. The produced dyes were applied to different fibres, such as sheep wool and goat hair with two Schiff bases synthesised from salicylaldehyde either with 2 -aminophenol or 2 -aminobenzyl alcohol. Also the investigation includes the effect of mordant type on the dyeing process.
\end{abstract}

\section{Keywords}

Dyes; 2-Aminophenol; 2-Aminobenzyl Alcohol; Salicylaldehyde; Schiff Bases; Complexation

\section{Introduction}

\subsection{Background of the Schiff Bases chemistry}

In spite of the fact that salicylaldehyde and substituted benzaldehyde compounds can react with substituted phe-

\footnotetext{
${ }^{*}$ Corresponding authors.
}

How to cite this paper: Abuamer, K.M., Maihub, A.A., El-Ajaily, M.M., Etorki, A.M., Abou-Krisha, M.M. and Almagani, M.A. (2014) The Role of Aromatic Schiff Bases in the Dyes Techniques. International Journal of Organic Chemistry, 4, 7-15. 
nol, such as 2-aminophenol or 2-aminobenzyl alcohol to form Schiff base which can be introduced to the transition metal ions as coordination chemistry application. The formation of azomethine group and a large number of Schiff bases and their complexes, which have received considerable attention, and became an important subject in the areas of coordination chemistry, biology and pharmaceutical science, were synthesized and investigated. Most of substituted benzene and aromatic moiety were investigated to be antibacterial and anticancer agents. [1]-[3].

Numerous Schiff bases and complexes have been synthesized and studied for the interesting and important properties, such as biological activity, catalytic activity in hydrogenation of olefins, transfer of an amino group, photochromic properties and complexation ability towards some toxic metals. Most chemists and scientific researchers and authors have studied most of the applications in a matter of biological properties of the Schiff base and their metal complexes to guarantee the best to use. For example, the $\mathrm{Cu}(\mathrm{II})$ complexes with two Schiff bases derived from 4-aminoantipyrine and salicylaldehyde or 2-thiophencarboxaldehyde as well as 5-methyl-2-thiophencarboxaldehyde, were found to be active against the strains of Staphylococcus aureus and Escherichia coli. The Schiff base, obtained from 2-thiophenecarboxaldehyde and 2-aminobenzoic acid and its metal complexes, shows antibacterial activity. N-Salicylideneanthranilic acid possesses antiulcer activity and the complexation with copper shows an increase in such activity [4]-[10].

Many transition metal complexes from this kind of Schiff bases have been synthesized, such as, Aluminum (III), Iron(III), Cobalt(II), Nickel(II) and Copper(II) complexes etc. These metal ions and others have been used as mordent in dyeing techniques. The principle of complexation and mordent has the same idea in coordination applications. The reaction of salicylaldehyde with anthranilic acid or o-aminophenol has been synthesized and investigated to justify the sites of coordination. This manor shows the engagement of the hydroxyl, amino and azomethine groups in the reaction [11], [12].

The aim of our present study is to synthesize and to introduce the Schiff base which engaged in the complexation to see the usefulness in dyeing techniques, in which the phenolic and benzylic hydroxyl groups involve these reactions. Metal complexes with a newly prepared Schiff base derived from salicylaldehyde (or salicylaldehyde derivatives) and 2-aminophenol or 2-aminobenzyl alcohol are the subjects of the comparison. The chemical structures of the Schiff bases were proposed in Figure 1. Different physiochemical techniques were used for the identification and study of the properties of such compounds. The most important factors account for being the planar chemical conformation which justifies the color and hard/soft properties of the sites of the reaction of Schiff bases [13], [14].

Despite their overall structural similarity, the type of the engagement of the hydroxyl groups and the metal ions in bonding facilitate the action that is required for the purpose of staining or dyeing. The directionality in the coordination justifies the sites, the parts and the groups that can be worked in bonding. The best sites of coordination in this manor are the hydroxyl groups rather than the azomethine group, as long as these groups in appropriate positions. The difference in the location and properties of the hydroxyl groups might give this Schiff bases advantages to be remarkable good agents for the assigned purposes. As the difference of hydroxyl groups work in certain fields, such as biological activities, they work in other fields. The analytical methods of characterization such as CHN percentage compositions of the Schiff bases and complexes were determined by using microchemical analytical methods on Perkin Elmer-240C (USA) elemental analyzer. Infrared spectra of this ligand was carried out by using $\mathrm{KBr}$ in the range $\left(4000-400 \mathrm{~cm}^{-1}\right)$ on Perkin Elmer Infrared model-337 [15], [16].

\subsection{Background of the Synthetic Dyes}

The first recorded synthetic dye was picric acid, which was produced in the 1770's from the interaction of in-<smiles>OCc1ccccc1/N=C/c1ccccc1O</smiles>

(Schiff I)<smiles>Oc1ccccc1/C=N/c1ccccc1O</smiles>

(Schiff II)

Figure 1. Chemical structures of the Schiff bases. 
digo and nitric acid. The discovery of benzene by Faraday in 1824, and its discovery as a constituent of coal tarby Leigh in 1842, had passed largely unnoticed. It was really the work of A. W. Hofmann, from 1845 onwards, that focused the attention of organic chemists on benzene and other such aromatic compounds obtained from coal tar. He had been able to isolate appreciable quantities of benzene and other interesting aromatic compounds from coal tar by fractional distillation. W. H. Perkins, a British Chemist, whilst working with Hofmann, discovered Mauveine, in 1856 at the age of 18, and thereby started the "dyestuff revolution". However, he was not intentionally working towards preparing synthetic dyestuffs but towards quinine. Since then the significant dyes discovered were Azo dyes in 1858 by Griess, alizarin red, 1868, etc. A lot of applications of synthetic colors have been applied to natural products as we can see the following Scottish Blackface Sheep stained with orange colored or the other applications [17].

There are many synthetic dyes available now. Their tinctorial strength, concentration, color range and color fastness, particularly to light and detergents, make them superior to natural dyes for nearly all uses. They are relatively cheap and have other advantages, for example; mordants may not be necessary, and they can color synthetic fibres. Manufacturers and processors using dyes have to deal with potential health, effluent disposal and other environmental requirements, usually to statutory limits [18].

\subsection{Classification of Synthetic Dyes}

This classification of dyes based on many ways such as according to the chemical structure, the chromophoric system or other systems. These systems of classification have many advantages. It readily identifies the dyes as belonging to a group, which has specific characteristic properties, and it is the classification used most widely by both the dye chemists and the dye manufacturers. There is another classification according to the applications [19]. The classes of dyes are defined by the application or end-use, and hence, the terms most applicable to textile dyeing are: Acid dyes, Basic dyes, Direct (Substantive) dyes, Mordant dyes, Vat dyes, Reactive dyes, Disperse dyes, Azo dyes, Anthraquinone dyes, Ingrain dyes, Sulphur dyes, Solvent dyes, Metal-complex dyes, Food dyes. A number of other classes have also been established including oxidation bases (mainly hair and fur) and leather dyes etc.

\subsection{Chemistry of the Dyes}

Chemists have been intrigued by the relationship between the color of a dye and its molecular structure. Because of these early days, the subject has been of special academic interest to those fascinated by the origin of color in organic molecules. In addition, an understanding of color and constitution relationships has always been of critical importance in the design of new dyes, perhaps the most notable early contribution to the science of the color referred to as the chromophore and the auxochromes [20].

The theory built on the principle of chromophore is commonly an electron-withdrawing group. Auxochromes are usually electron-releasing groups and they are linked to one another through a conjugated system. In essence, the concept of the donor-acceptor chromogen was born. Furthermore, it was observed that a bathochromic-shift of the color, i.e. the absorption band shifted to longer wavelength, might be obtained by increasing the electron-withdrawing power of the chromophore, by increasing the electron-releasing power of the auxochromes and by extending the length of the conjugation. The chromophore and auxochrome theory is proposed as a simple method for explaining the origin of color in dye molecules, although it lacks rigorous theoretical justification. The most important chromophores, as defined in this way, are the carbonyl $(\mathrm{C}=\mathrm{O})$, diazo $(-\mathrm{N}=\mathrm{N}-)$, azomethine $(-\mathrm{CH}=\mathrm{N})$ and nitro $\left(\mathrm{NO}_{2}\right)$ groups. Other groups increase the intensity of the color and shift the absorption to longer wavelengths of light, including hydroxyl $(\mathrm{OH})$ and amino $\left(\mathrm{NR}_{2}\right)$ groups. The concept may be applied to most chemical classes of dye, including azo, carbonyl, azomethine and nitro dyes [21].

\subsection{Methods of Colors and Types of Yarn Fibres}

The color change and the fastness properties of the dyed samples were determined using Standard Blue Scale and the Standard Gray Scale. Most fabrics are constructed from yarns, which in turn, are made from fibres. Over thousands of years, humans have learnt to twist fibres together to form yarns. Natural fibres come in various lengths, and this is often referred to as staple length. Synthetic fibres are manufactured, known as filaments [22]. The protein fibres have the fragments shown in Figure 2. 
<smiles>[R]C(NC(=O)C([R])NC(C)=O)C(C)=O</smiles>

Figure 2. Chemical structure of protein fibre.

\subsection{Mordants}

Some dyes and pigments, requiring a mordant to fix to the fabric, prevent the color from either fading with exposure to light or washing out. These compounds bind the dyes to the fabric by forming a chemical bridge. Mordant can also determine how the dye reacts to the fibre, resulting in several colors. The chemical names of some mordants are the metal salts such as, ammonium aluminium sulphate, Potassium aluminium sulphate, Potassium dichromate, Copper(II) sulphate, Iron(II) sulphate etc. Mordant can be pre-mordant, one-bath method or post mordant.

\subsection{Mechanism of Bonding}

Dyeing in general is carried out in aqueous solution. The chemistry of bonding of dyes to fibres is a complexation reaction. The process of attachment of the dye molecule to the fibre is one of adsorptions. It involves direct bonding, by ionic forces (hydrophobic interactions), hydrogen bonds, covalent linkages and "Van der Waal" forces. The presence of certain functional groups in suitable positions in the dye molecule causes its coordination. Figure 3 shows the coordination complex between the fibre mordant and dye, when alizarin binds to cotton. Natural dyes work best with natural fibres such as cotton, linen, wool, silk, jute, ramie and sisal. Among these, wool takes up dyes most easily followed by cotton, linen, silk and then the coarse fibres such as sisal and jute. Nearly all of them require some sort of a mordant [23].

\section{Materials and Methods}

\subsection{Chemicals and Reagents}

All the chemicals used were of laboratory grade including absolute ethanol, salicylaldehyde, 2-aminophenol, 2aminobenzyl alcohol and ammonium hydroxide. Aluminium ammonium sulphate (alum) [ $\left.\mathrm{Al}\left(\mathrm{NH}_{4}\right)\left(\mathrm{SO}_{4}\right)_{2} \cdot 12 \mathrm{H}_{2} \mathrm{O}\right]$, Tin chloride [ $\left.\mathrm{SnCl}_{2}\right]$, Potassium dichromate $\left[\mathrm{K}_{2} \mathrm{Cr}_{2} \mathrm{O}_{7}\right]$, Copper chloride $\left[\mathrm{CuCl}_{2} \cdot 2 \mathrm{H}_{2} \mathrm{O}\right.$, Nickel chloride $\left[\mathrm{NiCl}_{2} \cdot 6 \mathrm{H}_{2} \mathrm{O}\right]$, Iron chloride $\left[\mathrm{FeCl}_{3} \cdot 6 \mathrm{H}_{2} \mathrm{O}\right]$ and Iron sulphate $\left[\mathrm{FeSO}_{4} \cdot 7 \mathrm{H}_{2} \mathrm{O}\right]$, were used as mordants, soap powder. Ariel Gold plus (15\% - 30\% phosphate, 5\% - 15\% anionic surfactants, oxygen based bleaching agents, $5 \%$ cationic surfactants non-ionic surfactants), Polycarboxylates, Enzymes were used as a soap detergent. Distilled water was used in extraction and for preparation of all chemical solutions. Deionised water used for the dyeing process.

\subsection{Synthesis of the Schiff Bases}

Schiff base I: $0.02 \mathrm{~mol}(2.44 \mathrm{~g})$ of salicylaldehyde in hot ethanolic solution ( $30 \mathrm{ml})$ was added to $0.02 \mathrm{~mol}$ (2.48 g) of 2-aminobenzyl alcohol hot solution $(30 \mathrm{ml})$ step-wise with stirring. Reflux the mixture for $2 \mathrm{hr}$ period of time. Few drops of ammonium hydroxide may need to catalyse the reaction. A yellow solid Schiff base will precipitated.

Schiff base II: $0.02 \mathrm{~mol}$ ( $2.44 \mathrm{~g}$ ) of salicylaldehyde in hot ethanolic solution ( $30 \mathrm{ml}$ ) was added to $0.02 \mathrm{~mol}$ (2.18 g) of 2-aminophenol hot solution (30 ml) step-wise with stirring. Reflux the mixture for $2 \mathrm{hr}$ period of time. Few drops of ammonium hydroxide may need to catalyse the reaction. An orange solid Schiff base will precipitated.

The obtained precipitates were collected by filtration through Buchner funnel, washed and recrystallized using hot ethanol and then dried at room temperature, then putted in desiccator over anhydrous $\mathrm{CaCl}_{2}$. The yields recorded as $60 \%-70 \%$. The purity of the bases was checked by TLC using ethyl alcohol/benzene (1:3) as the solvent system. The dried Schiff bases are ready for the analysis.

\subsection{Fabric Materials}

Yarn fibres of wool, and hair threads of goat were used for each dyeing experiment. For display, fibre samples 


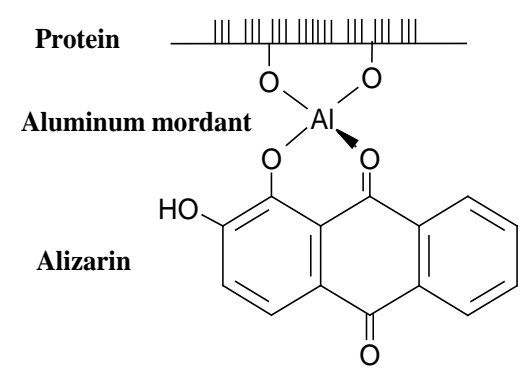

Figure 3. Formation of a coordinate complex between the cotton fibre and alizarin.

were cut into $4.5 \times 2 \mathrm{~cm}$ strips. The wool and goat hair were obtained from local source in Tripoli-Libya.

\subsection{Dyeing Procedure}

The dyestuff was extracted with boiling water by applying a bath liquor ratio of (g/ml). The duration of the extraction was fixed at 60 minutes.

\subsubsection{Dyeing without Mordant}

Yarn samples (wool, goat hair), were placed in a glass beaker of $1 \mathrm{~L}$ capacity containing $500 \mathrm{ml}$ of dyestuff and boiled for 60 minutes. The yarn samples were rinsed with distilled water and air dried.

\subsubsection{Dyeing after Treatment with a Mordant:}

Wool and goat hair samples were boiled with alum mordant in distilled water $(5 \mathrm{~g} / \mathrm{l})$ for 20 minutes. Then, the mordanted fibres and the dyeing both solutions were putted together in the dyeing beaker for 60 minutes. After dyeing, the unfixed dyestuff was removed by rinsing with cold water, and then air dried as shown in Plate 1. The same procedure was followed for other mordant dyeing.

\section{Results and Discussion}

The obtained results in dyeing with the Schiff base-I is summarized in Table 1, shows the effects on wool and goat hair samples. The differences can be also seen in Table 2 for the differences on the wool and the goat hair samples in dyeing with Schiff base-II.

\subsection{Fastness Properties}

\subsubsection{Hand Washing}

Dyed and undyed fabric samples in contact were agitated in a soap solution (Ariel, Egypt) (0.5 g/l) for 20 minutes at $40^{\circ} \mathrm{C}$. After rinsing and drying, the change in color of the dyed samples and the bleeding to the white fabric (cotton, silk, satin) was determined visually and the test shown in Plate 2. The changes were graded with marks 1 - $5(1$ = poor, 5 = excellent $)$.

\subsubsection{Light Fastness to Sun Daylight}

The test is used to determine wither a textile changes color or the color is destroyed by the action of daylight. The samples of the dyed fibres are exposed to daylight under standard conditions, including protection from rain, along with eight dyed wool standards according to BS EN ISO 105 B02. Change in color of the dyed samples related to standard scale of blue dyeing were assessed in the normal way visually by giving grade marks 1 - 8 (1 = poor, $8=$ excellent), that is shown in Plate 3 .

\subsection{Effect of Mordants on Fastness Properties}

Wool yarn samples, with no mordant and which mordanted with $\mathrm{SnCl}_{2}, \mathrm{FeSO}_{4}$ and $\mathrm{FeCl}_{3}$ became darker after exposed to natural sunlight. In case of goat hair only $\mathrm{FeCl}_{3}$ mordanted became darker after exposed to natural sunlight. Wool yarn and goat hair samples dyed with Schiff bases-I and II without using mordants released color 
Table 1. Wool and goat hair samples in dyeing with Schiff base-I with different mordants.

\begin{tabular}{|c|c|c|c|c|c|c|c|c|}
\hline Mordant & $\begin{array}{l}\text { (wool) } \\
\text { Color }\end{array}$ & $\begin{array}{l}\text { Wash } \\
\text { fast }^{*}\end{array}$ & $\begin{array}{l}\text { Light } \\
\text { fast }^{*}\end{array}$ & Mordant & $\begin{array}{l}\text { (goat hair) } \\
\text { Color }\end{array}$ & $\begin{array}{l}\text { Wash } \\
\text { fast }^{*}\end{array}$ & $\begin{array}{l}\text { Light } \\
\text { fast }^{*}\end{array}$ & Score \\
\hline Nil & Pale yellow & $4-5$ & 5 & Nil & Pale yellow & - & - & 9.5 \\
\hline $\mathrm{SnCl}_{2}$ & Beige yellow & 5 & 5 & $\mathrm{SnCl}_{2}$ & Beige yellow & 5 & 5 & 20 \\
\hline Alum & Cream & 5 & 5 & Alum & Cream & 5 & $4-5$ & 19.5 \\
\hline $\mathrm{K}_{2} \mathrm{Cr}_{2} \mathrm{O}_{7}$ & Olive green & 5 & 5 & $\mathrm{~K}_{2} \mathrm{Cr}_{2} \mathrm{O}_{7}$ & Olive green & 5 & 5 & 20 \\
\hline $\mathrm{CuCl}_{2}$ & Lime green & 5 & 5 & $\mathrm{CuCl}_{2}$ & Lime green & 5 & 5 & 20 \\
\hline $\mathrm{NiCl}_{2}$ & Lemon yellow & 5 & 5 & $\mathrm{NiCl}_{2}$ & Lemon yellow & 5 & 5 & 20 \\
\hline $\mathrm{FeSO}_{4}$ & Pale brown & 5 & 5 & $\mathrm{FeSO}_{4}$ & Pale brown & 5 & $4-5$ & 19.5 \\
\hline $\mathrm{FeCl}_{3}$ & Beige brown & 5 & 5 & $\mathrm{FeCl}_{3}$ & Beige brown & 5 & 5 & 20 \\
\hline \multicolumn{9}{|c|}{ Total Scores $=148.5$} \\
\hline
\end{tabular}

* = 1-very poor, 2-poor, 3-fair, 4-very fair, 5-good, 6-very good.

Table 2. Wool and goat hair samples in dyeing with Schiff base-II with different mordants.

\begin{tabular}{ccccccccc}
\hline Mordant & (wool) Color & Wash fast & Light fast & Mordant & (goat hair) Color & Wash fast & Light fast & Score \\
\hline $\mathrm{Nil}$ & Orange & $4-5$ & 5 & $\mathrm{Nil}$ & Orange & - & - & 9.5 \\
$\mathrm{SnCl}_{2}$ & Tan cream & 5 & $4-5$ & $\mathrm{SnCl}_{2}$ & Tan cream & 5 & 5 & 19.5 \\
$\mathrm{Alum}$ & Lemon yellow & 5 & 5 & $\mathrm{Alum}$ & Lemon yellow & 5 & 5 & 20 \\
$\mathrm{~K}_{2} \mathrm{Cr}_{2} \mathrm{O}_{7}$ & Chocolate brown & 5 & 5 & $\mathrm{~K}_{2} \mathrm{Cr}_{2} \mathrm{O}_{7}$ & Chocolate brown & 5 & $4-5$ & 19.5 \\
$\mathrm{CuCl}_{2}$ & Olive & 5 & 5 & $\mathrm{CuCl}_{2}$ & Olive & 5 & 5 & 20 \\
$\mathrm{NiCl}_{2}$ & Turmeric yellow & 5 & 5 & $\mathrm{NiCl}_{2}$ & Turmeric yellow & 5 & 5 & 20 \\
$\mathrm{FeSO}_{4}$ & Cinnamon brown & 5 & 5 & $\mathrm{FeSO}_{4}$ & Cinnamon brown & 5 & 5 & 20 \\
$\mathrm{FeCl}_{3}$ & Brown & 5 & $4-5$ & $\mathrm{FeCl}_{3}$ & Brown & 5 & 5 & 19.5 \\
& & \multicolumn{7}{c}{ Total Scores } \\
\end{tabular}

${ }^{*}$ = 1-very poor, 2-poor, 3-fair, 4-very fair, 5-good, 6-very good.

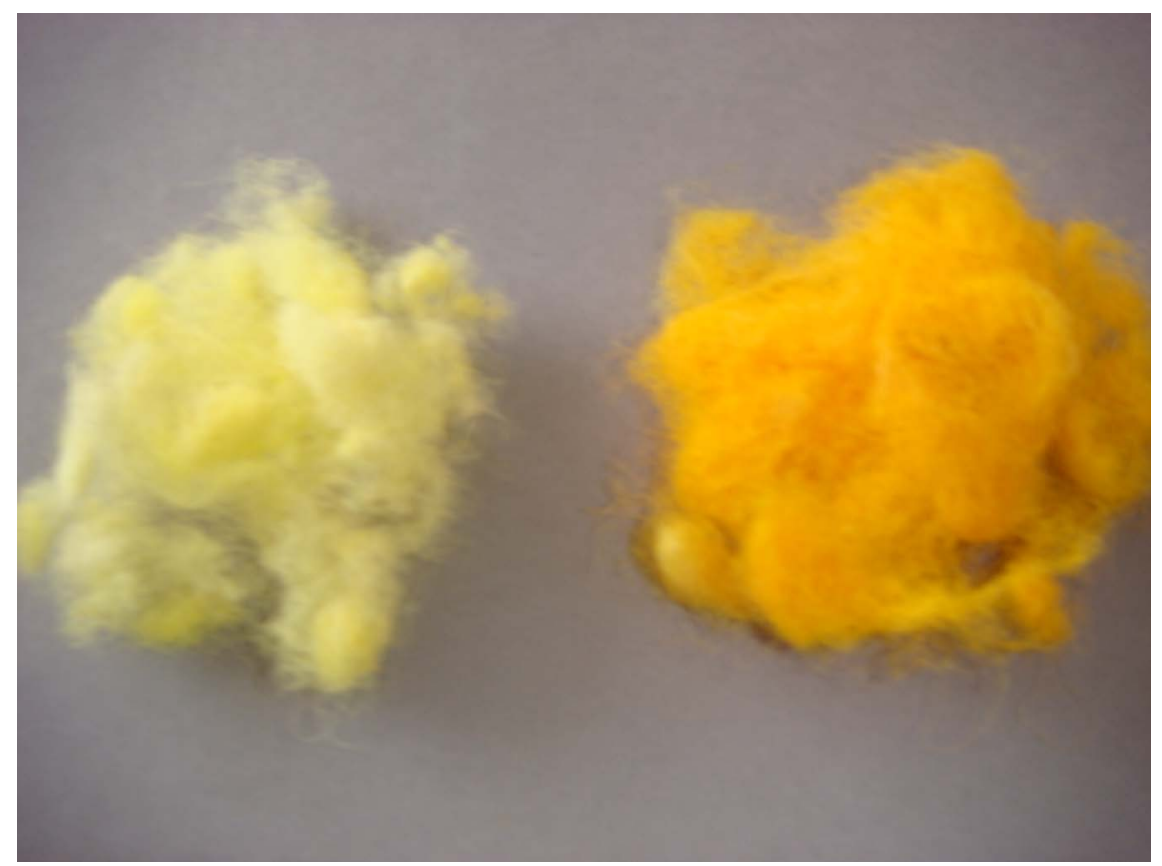

Plate 1. Wool samples dyed with Schiff base-I and II without mordants. 


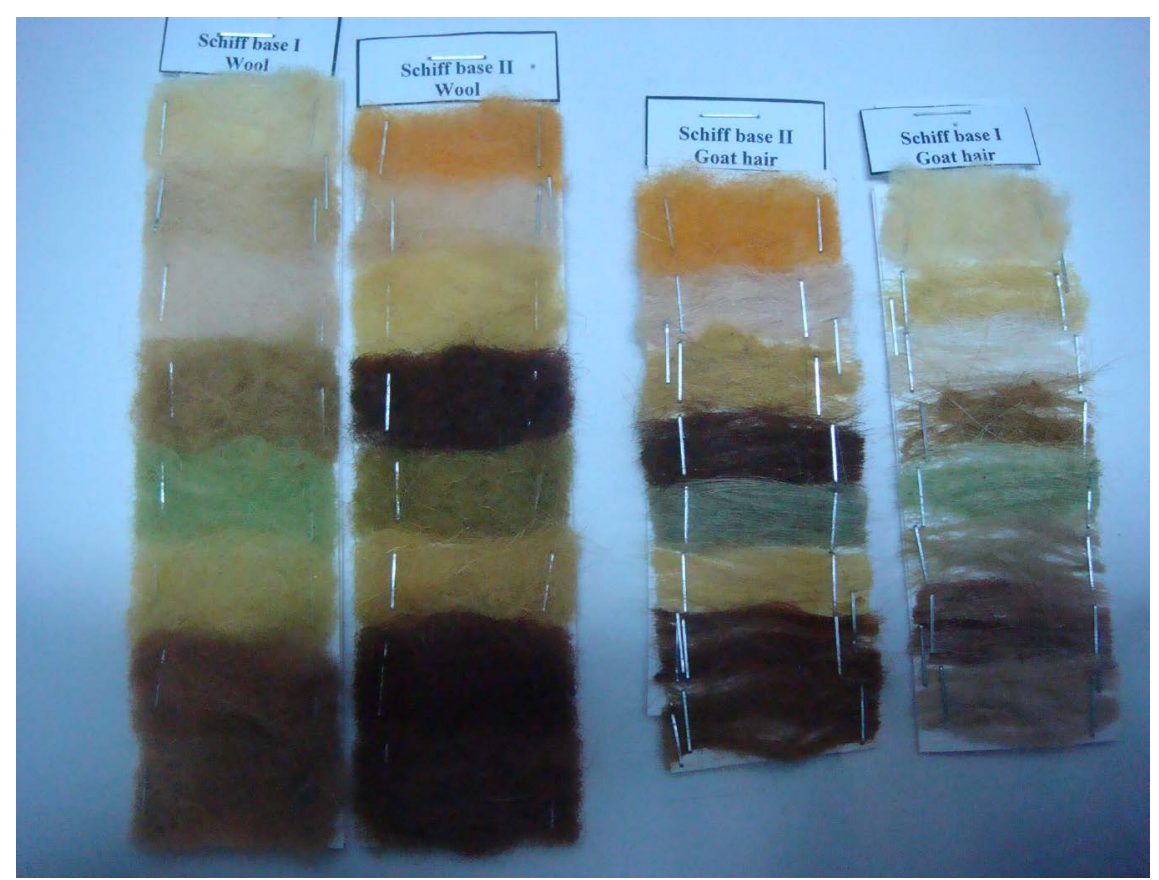

Plate 2. Dyes samples of Schiff bases-I and II with metal mordants, prepared for light fastness.

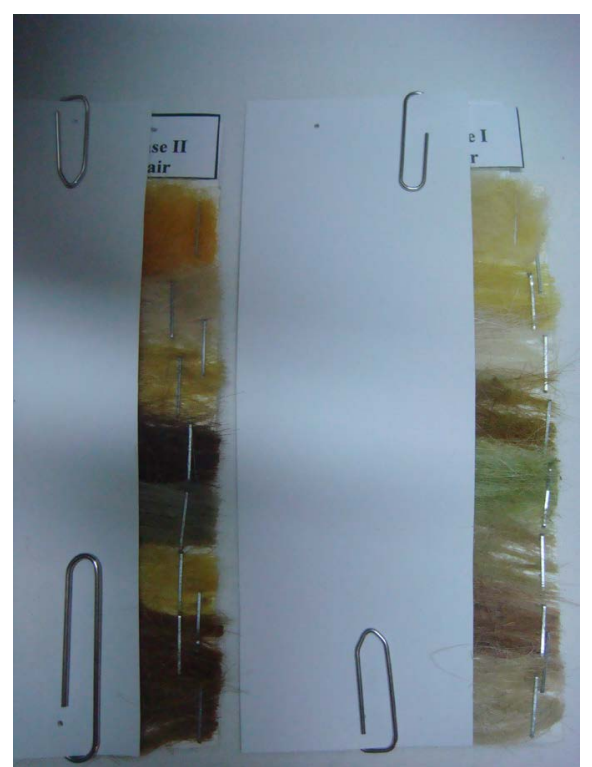

(a)

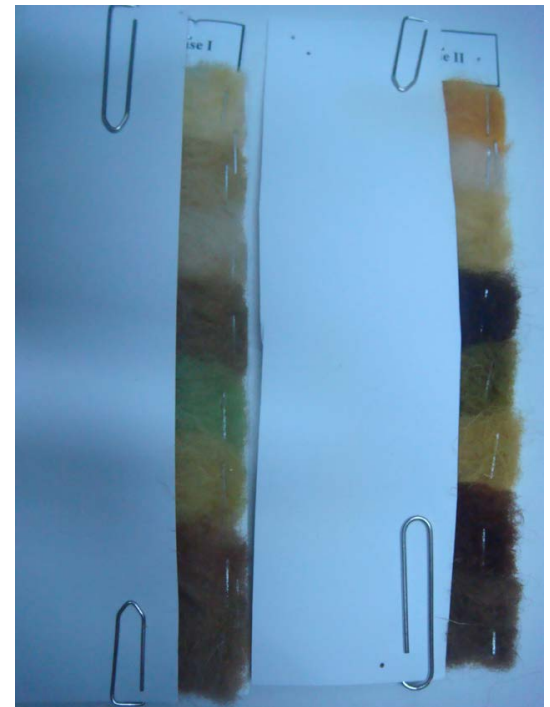

(b)

Plate 3. Samples exposed to natural sunlight for light fastness tests.

when washed with detergent soap. The effect of hand washing is shown in Plate 4.

\subsection{Dyeing Properties of Dyes}

The disperse dyes were applied to the mentioned fibers. The dyes gave excellent uniformity of coloration on fabrics and the overall fastness properties of the dyes are shown in tables. These dyes gave these excellent results with respect to levelness on the fabric. The variation in the results from both the nature and position of the subs- 


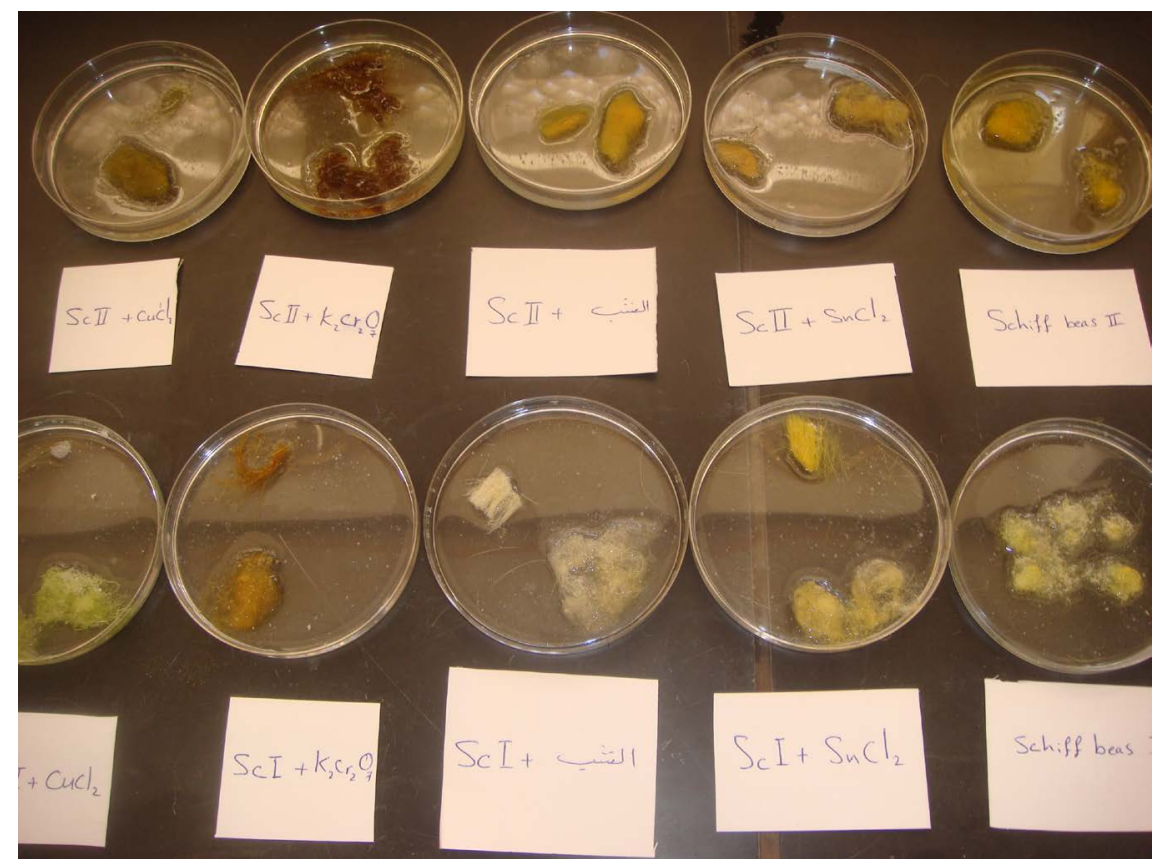

Plate 4. Hand washing of dyed samples.

tituent present on the diazotized compound. The results of the exhaustion of the dye bath and the fixation of the dyed fabric are given in the previous tables.

\section{Conclusion}

Hydroxyl or azomethine groups of Schiff bases can coordinate to metal ions, either by coordination or by forming ionic bonds. This interaction occurs with the metal ions either as free ions or as mordants in dye techniques. However, we believe that the directionality in the coordination limits the azomethine group to engage in the case of the dyes, since there are changes occuring in the comparison of the colors obtained, as well as its location which prevents it from doing so. As we can imagine, the phenolic hydroxyl group interacts rather better than the benzyl hydroxyl group from the color appearance. The light and wash fastness of all patterns dyed with disperses dyes show fairly very good fastness properties. The shades of the fabric given in the results are based on the standard Paint Shade Card as in Hue scale.

\section{References}

[1] Franco, E., Torres, E., Mendiola, M. and Sevilla, M. (2000) Synthesis, spectroscopic and voltammetry studies of copper(II) complexes with open chain, cyclic and a new macrocyclic thiosemicarbazones. Polyhedron, 19, 441-451. http://dx.doi.org/10.1016/S0277-5387(99)00383-6

[2] Barton, D. and Ollis, W. (1979) Comprehensive organic chemistry. 3rd Edition, Pergamon press Ltd., Oxford.

[3] Maihub, A., El-ajaily, M. and El-hassy, N. (2012) Titanium(IV), Chromium(III) and Iron(III) complexes of Schiff base derived from aldehyde and primary amine. International Journal of Chem Tech Research, 4, 631-633.

[4] Negoiu, M., Pãsculescu, S., Roau, T., Georgescu, R. and Drãghici, C. (2010) Synthesis and characterization of complex $\mathrm{Cu}(\mathrm{II})$ combinations with Schiff base ligands derived from 4-amino-1-phenyl-2,3-dimethyl-3-pyrazole-5-one and pentaatomic heterocyclic aldehydes. Revista de Chimie (Bucharest), 61, 762-766.

[5] Olie, G. and Olive, S. (1984) The chemistry of the catalyzes hydrogenation of carbon monoxide. Springer, Berlin.

[6] Dugas, H. and Penney, C. (1981) Bioorganic chemistry. Springer, New York. http://dx.doi.org/10.1007/978-1-4684-0095-3

[7] Margerum, J. and Miller, L. (1971) Photochromism. Interscience, Wiley, New York.

[8] Sawodny, W. and Riederer, M. (1977) Addition compounds with polymeric Chromium(II)-Schiff base complexes. Angewandte Chemie International Edition in English, 16, 859-860. http://dx.doi.org/10.1002/anie.197708591 
[9] Mohamed, G., Omar, M. and Hindy, A. (2005) Synthesis, characterization and biological activity of some transition metals with Schiff base derived from 2-thiophene carboxaldehyde and aminobenzoic acid. Spectrochimica Acta, 62, 1140-1150. http://dx.doi.org/10.1016/j.saa.2005.03.031

[10] Parashar, R., Sharma, R. and Mohan, G. (1989) Biological activity of some Schiff bases and their metal complexes. Biological Trace Element Research, 23, 145-150. http://dx.doi.org/10.1007/BF02917185

[11] Maihub, A., El-Ajaily, M. and Hudere, S. (2007) Synthesis and spectral studies of some transition metal complexes of Schiff base. Asian Journal of Chemistry, 19, 1-4.

[12] El-Ajaily, M. and Maihub, A. (2010) Synthesis and spectroscopical characterization of Mn(II)-benzoin complex. International Journal of Chem Tech Research, 2, 1579-1580.

[13] El-Ajaily, M., Maihub, A., Etorki, A., Ben-Saber, S. and Elmajani, M. (2013) Coordination behavior of phenolic and benzylic hydroxyl groups in complexation of their Schiff bases with Zn(II) and Cd(II) ions. Journal of Pharmaceutical and Biomedical Sciences, 8, 695-697.

[14] Singh, M., Singh, P. and Gupta, A. (2009) Facile one-pot synthesis of tricyclicdibenzodioxazocine-2-ones and other higher homologues. Arkivoc, 7, 189-196. http://dx.doi.org/10.3998/ark.5550190.0010.718

[15] Jesmin, M., Ali, M. and Khanam, J. (2010) Antitumour activities of some Schiff bases derived from benzoin, salicylaldehyde, amino phenol and 2,4 dinitrophenyl hydrazine. Thai J. Pharm.Sci., 34, 20-24.

[16] Mounika, K., Anupama, B., Pragathi, J. and Gyanakumari, C. (2010) Synthesis, characterization and biological activity of a Schiff base derived from 3-ethoxy salicylaldehyde and 2-amino benzoic acid and its transition metal complexes. Journal of Scientometric Research, 2, 513-524.

[17] Gordon, P. and Gregory, P. (1983) Organic chemistry in color. Springer-Verlag, Berlin, Heidelberg, New York.

[18] Christie, R. (2001) Color chemistry. Royal Society of Chemistry, Cambridge.

[19] Allen, R. (1971) Color chemistry, studies in modern chemistry. Nelson, London.

[20] Goodwin, J. (1982) A dyer’s manual. Pelham Books Ltd., London.

[21] Bailey, P. and Bailey, C. (1989) Organic chemistry. Allyn and Bacon, Inc., Boston.

[22] Trotman, E. (1964) Color chemistry. Griffin and Company Ltd., London.

[23] Vankar, P. (2000) Chemistry of natural dyes. Resonance, 5, 73-80. http://dx.doi.org/10.1007/BF02836844 